\title{
Spotlight on measles 2010: A measles outbreak in a Roma population in Pulawy, eastern Poland, June to August 2009
}

H Orlikova (horlikova@pzh.gov.pl)1,2, J Rogalska ${ }^{1}$, E Kazanowska-Zielinska ${ }^{3}$, T Jankowski ${ }^{3}$, J Slodzinski ${ }^{4}$, B Kess ${ }^{4}$, P Stefanoff ${ }^{1}$

1. Department of Epidemiology, National Institute of Public Health - National Institute of Hygiene (NIZP-PZH), Warsaw, Poland

2. European Programme for Intervention Epidemiology Training (EPIET), European Centre for Disease Prevention and Control (ECDC), Stockholm, Sweden

3. State District Sanitary Inspectorate, Pulawy, Poland

4. State Regional Sanitary Inspectorate, Lublin, Poland

We describe a local indigenous outbreak of measles in a susceptible Roma community, which occurred in Pulawy, a town of 50,000 citizens in the Lubelskie province (eastern Poland) during summer 2009. From 22 June to 30 August 2009, 32 measles cases were reported, and additionally nine possible cases were actively identified. A mass immunisation campaign was organised to stop measles transmission in the Roma community. Active surveillance of rash-febrile illnesses allowed documentation of the impact of mass immunisation in preventing further measles spread in the Roma community, and the surrounding population of Pulawy.

\section{Outbreak notification}

Between 26 June and 21 July 2009, 14 measles cases were reported by physicians to the public health authority in Lubelskie province, Poland. All affected persons were from a Roma community living in the town of Pulawy. No measles cases had been registered during the previous decade until 2008, when six cases were notified in the same Roma community in Pulawy.

The investigation suggested common exposure between the first reported cases. The index case was a Roma resident of Pulawy. On 20 June he returned from the city of Lodz, where he had been was in contact with a Roma person who had recently returned from England with rash illness (this case had not been reported to the Polish national surveillance). On 22 June he developed typical symptoms of measles, subsequently confirmed serologically, and was admitted to hospital on 26 June.

\section{Outbreak investigation}

An outbreak investigation team was formed comprising epidemiologists and public health officers at district, regional and national level.
Case definitions were set up as follows:

- Possible case: each person who resided in the town of Pulawy after 15 June 2009 and who developed febrile illness with rash;

- Probable case: each person, who fulfilled the criteria of a possible case, and for whom an epidemiological link to a confirmed case was ascertained;

- Confirmed case: each person who fulfilled the criteria of a possible case, and in whom measles was confirmed by serological (ELISA IgM) or virologal test (virus isolation or PCR).

Active case finding was implemented simultaneously. We reviewed the medical documentation from all primary healthcare facilities in Pulawy since mid-June retrospectively, to search for cases of rash-like illness, which could indicate undiagnosed measles transmission occurring inside or outside the Roma community. Beginning from 10 August 2009, enhanced surveillance was set up, requesting primary healthcare and hospital physicians to report all new rash-febrile cases, and to send weekly reports including all suspected cases or zero reporting.

\section{Outbreak description}

From 22 June until 30 August 2009, 41 cases were registered, of whom $32(78 \%)$ were reported through the routine surveillance, and nine were actively found. According to the case definition, eight (19\%) of the 41 cases were classified as confirmed, 24 (59\%) as probable and nine (22\%) as possible. The shape of the epidemic curve (Figure 1) indicated person-to-person propagation, with several transmission chains.

Of 41 registered cases, 35 (85\%) were of Roma ethnicity, residing in two localities in Pulawy inhabited by the local Roma community. In addition, one occupational case was reported in a Polish hospital nurse working 
in the department of infectious diseases of the district hospital in Pulawy. A further five non-Roma cases were notified, all of whom were actively found and classified as possible cases.

Among the 32 confirmed or probable cases, 13 (41\%) were female (Figure 2). The mean age was 12 years (range: three months to 49 years) and the median age was 12 years. Four infants (12\%) and nine adults (28\%) were among the 32 .

Twenty two of $32(69 \%)$ patients were hospitalised in the department of infectious diseases at district hospital in Pulawy and the others were treated in primary healthcare. Practically all 32 confirmed or probable cases developed typical erythematous maculopapular rash, fever $>38^{\circ} \mathrm{C}$ and cough. Most of the patients had Koplik spots, coryza and conjunctivitis. Four cases, all of them unvaccinated, of whom one was classified as confirmed and three as probable, experienced severe complications; namely, three patients had pneumonia and one infant had myocarditis, encephalitis and pneumonia. All patients recovered and no fatal cases were registered. The nine cases that were classified as possible cases had very mild symptoms with rash and fever, and none of them were hospitalised.

\section{Laboratory results}

Biological samples from eight cases were tested in the laboratory, and all were confirmed as measles-positive at the National Reference Laboratory for Measles and Rubella of the National Institute of Public Health in Warsaw, three serologically (ELISA IgM-positive) and five by detection of measles virus (one through virus isolation, five through PCR testing). Genotype D4 isolate Pulawy.POL/28.09 was confirmed from two cases, detected at the World Health Organisation's European Regional Reference Laboratory for Measles and Rubella at the Robert Koch Institute in Berlin.

\section{Vaccination status of cases}

From a total of 32 confirmed or probable cases, 28 were not previously immunised, including five infants (between three and 13 months) who were not vaccinated because of young age. Only one, a 1.5-year-old boy, was previously vaccinated (three months before onset) with one dose of measles-containing vaccine. Three persons received their first dose during the mass

\section{FIGURE 1}

Measles cases by day of onset (two-day intervals) and by classification, Pulawy, 2009 (n=41)

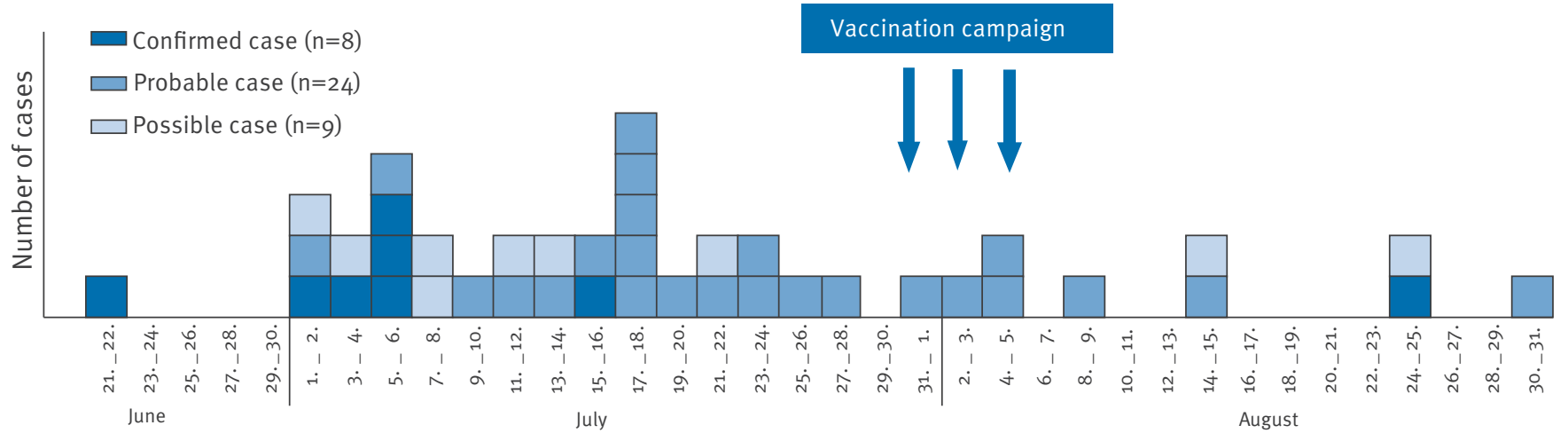

FIGURE 2

Confirmed and probable cases of measles by age group and gender, Pulawy, 2009 (n=32)

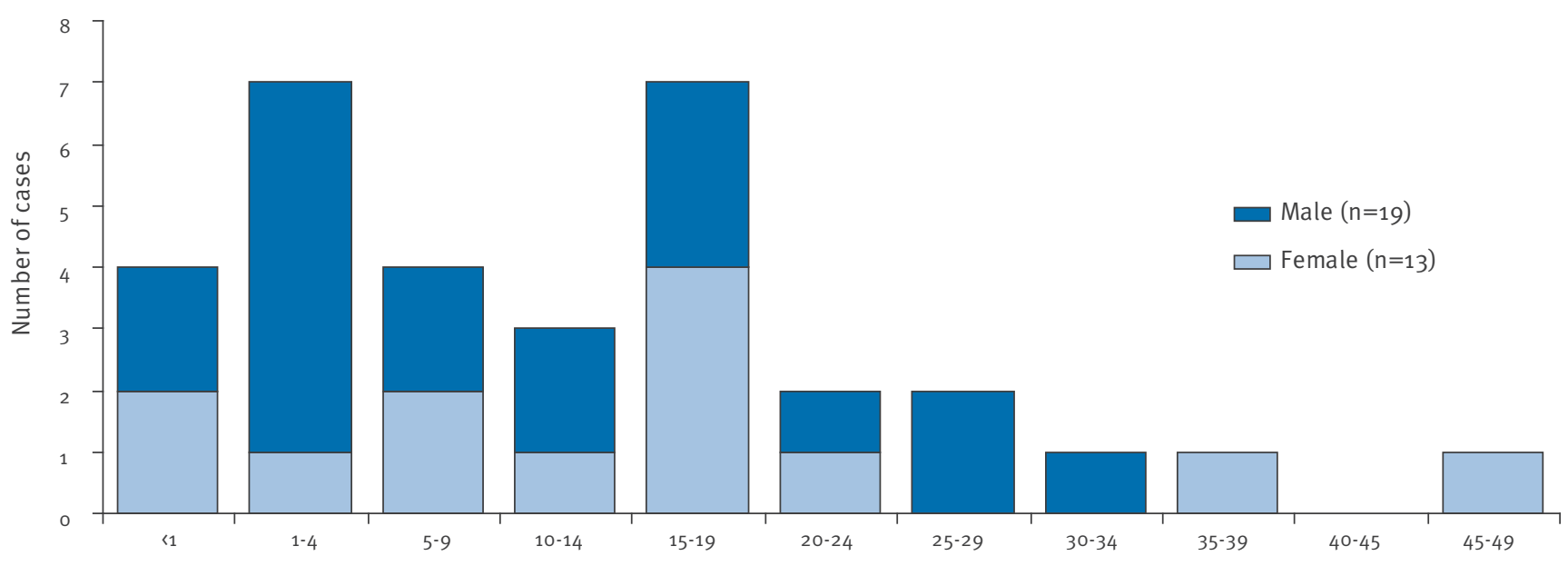


vaccination campaign that was initiated as a control measure to interrupt the spread of the outbreak. They had onset of measles four to five days after the vaccine administration (Figure 3). Among the nine possible cases, seven were previously vaccinated.

\section{Control measures}

As a response to stop the spread of the measles outbreak, the district sanitary inspectorate in Pulawy, with the support from regional sanitary inspectorate in Lublin and the National Institute of Public Health, organised a mass vaccination campaign. It was directed to the Roma residents of Pulawy, between the ages of nine months and 60 years. The invitation to the mass immunisation in Polish language was disseminated to the Roma community leaders, and through primary health units in Pulawy. It was held at a primary healthcare centre in the proximity of the Roma community, on 31 July, and on 3 and 4 August. From around 300 Roma registered at the municipality of Pulawy, 195 (102 individuals under the age of 20 years and 93 adults) attended the vaccination point and 138 (55 individuals under the age of 20 years and 83 adults) received a dose of combined measles, mumps and rubella (MMR) vaccine [1]. The reasons for exclusion of some attendants from vaccination were the following: a documented full previous vaccination $(n=16)$, young age under nine months $(n=3)$, pregnancy $(n=3)$, breastfeeding shortly

\section{FIGURE 3}

Vaccination status of confirmed and probable measles cases by age-group, Pulawy, $2009(n=32)$

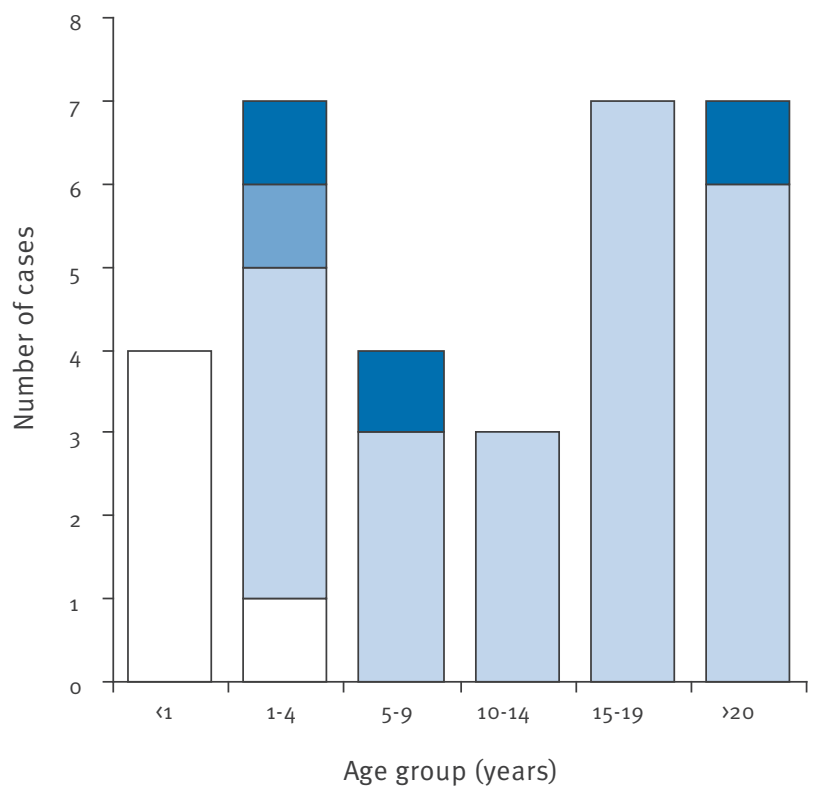

$\square$ Received a dose in vaccination campaign $(n=3)$

$\square$ Vaccinated - one dose $(n=1)$

$\square$ Not vaccinated $(n=23)$

$\square$ Not vaccinated (under age limit) $(n=5)$ after delivery $(n=1)$, confirmed or probable measles in summer 2009 or documented laboratory-confirmed measles ealier $(n=22)$, acute measles diagnosed during the campaign $(n=2)$, temporary contraindication due to an acute febille illness $(n=9)$, and waiting for an attestation of contraindication $(n=1)$.

Ongoing active febrile-rash illnesses surveillance was continued in all medical centers in Pulawy following the identification of the first case, until twice the maximum incubation period after the onset date of the last case. The district sanitary inspectorate in Pulawy informed local healthcare professionals about the outbreak and ongoing control measures. An article summarising the outbreak and control measures undertaken was published in the national surveillance bulletin. The public was provided with up-to-date information via local websites and press articles.

The regional sanitary inspectorate in Lublin implemented investigation of the Roma communities in Lubelskie province with regards to their vaccination status, and offering immunisation to all unvaccinated and incompletely vaccinated individuals or contacts of measles cases. For example, on 17 and 19 August 2009, 45 Roma were vaccinated with MMR vaccine in a focus area of measles in Opole Lubelskie and Poniatowa. A recommendation was issued to check the vaccination status of all 10-year-old school children in Pulawy at the beginning of the new school year.

\section{Discussion and conclusions}

This outbreak has been the largest indigenous cluster of measles in the past decade in Poland, affecting one tenth of the local Roma community. Infants, children and adults had measles and several patients had severe complications.

In addition to the standard procedures (treatment and isolation of cases, contact tracing, offering of postexposure vaccination until 72 hours after the contact), we implemented active case finding and organised a mass immunisation campaign as a response to this outbreak [1]. Moreover, vaccination coverage, size and age distribution of the Roma population in Pulawy was assessed, as described in a parallel article [2].

Factors that facilitated the spread of infection in the susceptible Roma population were low prior vaccination uptake, high contagiousness of measles, infection transmission lasting from between two and four days before to four days after rash onset, questionable home isolation of cases and numerous contacts inside the community. Children and adults fell ill, as described in other countries [3-5]. Several infants experienced measles at an age below the limit for the first vaccine dose in the national immunisation schedule. We observed several waves of propagation within the community. The herd immunity in the local Roma population was insufficient to stop the outbreak. Interruption of indig- 
enous measles transmission is considered one of the criteria for elimination [6].

The targeted mass immunisation was efficient in limiting measles transmission. Only five cases occurred after the campaign in the Roma community. Among them were three patients with onset of disease four to five days after administration of the vaccine. They had received their first dose during the campaign and were probably vaccinated during the incubation period. Two children with onset of disease after the campaign had not previously been immunised, one because of young age (under six months-old) and the other was referred to a neurologist and an allergist to verify the contraindication, but his parents did not take the child to see the specialists.

One additional case that occurred after the campaign targeted only to Roma, was the occupational infection of the hospital nurse reported in routine surveillance. This case could have been avoided if the nurse had been previously vaccinated. Ensuring that healthcare workers are adequately protected is a key requirement to prevent healthcare-associated measles infections [7].

All nine cases identified through the active surveillance, four were of Roma ethnicity and five non-Roma, were classified as possible cases. All nine had mild symptoms and were treated in an outpatient clinic. Most of them were found retrospectively. Seven of the possible cases had previously been vaccinated against measles, of whom six with one dose, and none were laboratory-tested for measles. It is therefore possible, that they may have had a different febrile-rash disease not necessarily caused by measles virus. Nevertheless, active case finding and inclusion of possible cases was useful in order to assess how far the outbreak might have spread. The active surveillance helped us in documenting that the mass vaccination effectively stopped transmission in the Roma community and that the nonRoma population was not or just marginally affected.

Based on the above evidence, we can conclude that due to high vaccination coverage in Poland's general population, large-scale spread of measles outside the Roma community was avoided. According to the official statistics for 2008, the vaccination coverage for the combined MMR vaccine was $98.4 \%$ for the first dose administered at the age of $13-15$ months, and $97.2 \%$ for the second dose given at the age of 10 years [8].

Poland belongs to the countries with moderate incidence of indigenous measles, with 0.1-0.3 cases per 100,000 population in the years 2006 to $2008[9,10]$. Fourteen percent of all cases in 2008 were imported [10]. In the current indigenous outbreak, the index case was infected in June 2009 when staying in the city of Lodz, where several measles cases were registered at the time [11]. The epidemiological investigation revealed contact with a person with a rash illness recently returned from England. This person was neither reported to the surveillance system nor identified by the index case, so remains unknown and no details regarding the travel history were obtained.

Only eight cases were laboratory-tested for measles during the outbreak, which is a quarter of the cases reported in routine surveillance and a third of the hospitalised ones. The proportion of laboratory-tested patients should be higher in the phase of measles elimination. However, samples were taken and confirmed from patients in almost every chain of transmission in the outbreak. The genotype D4 virus isolate Pulawy.POL/28.09, detected in the current outbreak, was identical with the isolates Wroclaw.POL/13.09 and Lodz.POL/27.09 in Poland and Hamburg.DEU/03.09 in North-West Germany from spring 2009 and differed by $1 \mathrm{nt}$ from the sequence of the isolate Enfield.GBR/14.07 circulating in England [11]. The Pulawy strain also shows sequence identity (100\%) to the virus detected in the current epidemic in Bulgaria [Regional Reference Laboratory WHO EURO, RKI, personal communication].

Several outbreaks of measles have been reported in many European countries within the past years, in particular in susceptible population groups such as orthodox Jewish communities [12], religious schools [13], anthroposophic communities $[14,15]$, traveller communities $[16,17]$ and in regional or national outbreaks involving a large proportion of Roma/Sinti [18], Roma migrant or indigenous populations $[3,4]$. Measles clusters in susceptible communities are a considerable public health problem. To reach the goal of measles elimination in Poland and other European countries, a stronger commitment by decision makers to improve vaccination coverage in all sections of the population is needed. Regional and national elimination strategies need to include steps to assess the accumulation of susceptible individuals and interrupt indigenous transmission [19].

Causes of low vaccination uptake must be defined. In the case of Roma communities we should consider factors that may contribute to the low vaccination coverage that was observed for example in Pulawy [2]. The reasons could be varied, such as socio-economical and cultural differences, level of education, language barriers, discrimination [20] or low awareness of vaccination as a preventive measure. Where there is limited access to healthcare, this must be improved. By organising the vaccination campaign in Pulawy, we have learned that for a public health intervention in the Roma population to be successful, it must be tailored and supported by Roma family and community leaders.

Education of public health and healthcare professionals must continue in the phase of measles elimination [21], and laboratory testing of febrile-rash illnesses is essential. 


\section{Recommendations}

1. Cooperation between local administrative authorities, social workers in contact with the Roma, primary healthcare workers and public health professionals is necessary in reaching Roma communities to prepare and implement public health interventions including suplementary immunisation activities.

2. Offering immunisation against measles to unvaccinated inhabitants in Pulawy and other towns in which inadequately vaccinated populations have been identified could prevent further outbreaks.

3. Surveillance of febrile-rash illnesses should be enhanced by enforcing laboratory testing of all suspected measles cases to document measles elimination in the present situation in Poland.

\section{Acknowledgements}

We thank all those involved in the outbreak investigation and vaccination campaign for good cooperation (State Regional Sanitary Inspectorate in Lublin and State District Sanitary Inspectorate in Pulawy, Local Administrative Authority in Pulawy and general practioner B. Goscimska and all nurses W. Gorska, J. Polak, T. Skorek). We would like to acknowledge A. Zielinski for his supervision regarding vaccination campaign. We thank kindly S. Santibanez and A. Mankertz from the WHO European Regional Reference Laboratory for Measles and Rubella at the Robert Koch Institute in Berlin for detailed virological analysis and A. Makowka who performed virus isolation and PCR testing at the Department of Virology in the National Institute of Public Health in Warsaw.

\section{References}

1. World Health Organization (WHO). WHO position on measles vaccines. Vaccine. 2009;27(52):7219-21. Available from: http:// www.ncbi.nlm.nih.gov/pubmed/19833246

2. Stefanoff P, Orlikova H, Rogalska J, Kazanowska-Zielinska $\mathrm{E}$, Slodzinski J. Mass immunisation campaign in a Roma settled community created an opportunity to estimate its size and measles vaccination uptake, Poland, 2009. Euro Surveill. 2010;15(17). pii=19552. Available from: http://www. eurosurveillance.org/ViewArticle.aspx?Articleld=19552

3. Marinova L, Kojouharova M, Mihneva Z. An ongoing measles outbreak in Bulgaria, 2009. Euro Surveill. 2009;14(26). pii=19259. Available from: http://www.eurosurveillance.org/ ViewArticle.aspx?Articleld=19259

4. Kaic B, Gjenero-Margan I, Kurecic-Filipovic S, Muscat M. A measles outbreak in Croatia, 2008. Euro Surveill. 2009;14(1) pii=19083. Available from: http://www.eurosurveillance.org/ ViewArticle.aspx?Articleld $=19083$

5. Peña-Rey I, Martínez de Aragón V, Mosquera M, de Ory F, Echevarría JE; Measles Elimination Plan Working Group in Spain. Measles risk groups in Spain: implications for the European measles-elimination target. Vaccine. 2009;27(30):3927-34. Available from: http://www.ncbi.nlm. nih.gov/pubmed/19376180

6. Martin R, Deshevoi S, Buddha N, Jankovic D. Approaching measles and rubella elimination in the European Region - need to sustain the gains. Euro Surveill. 2009;14(50). pii=19449. Available from: http://www.eurosurveillance.org/ViewArticle. aspx?Articleld=19449

7. Spika IS. Measles elimination 2010 target: the need to meet the specific risk group. Euro Surveill. 2006;11(10). pii=648. Available from: http://www.eurosurveillance.org/ViewArticle. aspx?Articleld $=648$

8. National Institute of Public Health - National Institute of Hygiene - Department of Epidemiology, Chief Sanitary Inspectorate - Department of Communicable Diseases Control. Vaccinations in Poland in 2008. Annual bulletin, 2009; 1-99. Available from: http://www.pzh.gov.pl/oldpage/epimeld/2008/ Sz_2008.pdf
9. Muscat M, Bang H, Wohlfahrt J, Glismann S, Mølbak K; EUVAC. NET Group. Measles in Europe: an epidemiological assessment. Lancet. 2009;373(9661):383-9. Available from: http://www. ncbi.nlm.nih.gov/pubmed/19131097

10. EUVAC.NET. Measles surveillance annual report 2008. EUVAC. NET 2009. Available from: http://www.euvac.net/graphics/ euvac/pdf/annual_2008.pdf

11. Rogalska J, Santibanez S, Mankertz A, Makowka A, Szenborn L, Stefanoff P. Spotlight on measles 2010: An epidemiological overview of measles outbreaks in Poland in relation to the measles elimination goal. Euro Surveill. 2010;15(17). pii=19549. Available from: http://www.eurosurveillance.org/ViewArticle. aspx?Articleld=19549http://

12. Lernout T, Kissling E, Hutse V, De Schrijver K, Top G. An outbreak of measles in orthodox Jewish communities in Antwerp, Belgium, 2007-2008: different reasons for accumulation of susceptibles. Euro Surveill. 2009;14(2). pii=19087. Available from: http://www.eurosurveillance.org/ ViewArticle.aspx?Articleld $=19087$

13. Noury U, Stoll J, Haeghebaert S, Antona D, Parent du Châtelet I, The investigation team. Outbreak of measles in two private religious schools in Bourgogne and Nord-Pas-de-Calais regions of France, May-July 2008 (preliminary results). Euro Surveill. 2008;13(35). pii=18961. Available from: http://www. eurosurveillance.org/ViewArticle.aspx?Articleld=18961

14. van Velzen E, de Coster E, van Binnendijk R, Hahné S. Measles outbreak in an anthroposophic community in The Hague, The Netherlands, June-July 2008. Euro Surveill. 2008;13(31). pii=18945. Available from: http://www.eurosurveillance.org/ ViewArticle.aspx?Articleld $=18945$

15. Schmid D, Holzmann H, Abele S, Kasper S, König S, Meusburger S, et al. An ongoing multi-state outbreak of measles linked to non-immune anthroposophic communities in Austria, Germany, and Norway, March-April 2008. Euro Surveill. 2008;13(16). pii=18838. Available from: http://www. eurosurveillance.org/ViewArticle.aspx?Articleld $=18838$

16. Cohuet S, Morgan O, Bukasa A, Heathcock R, White J, Brown K, et al. Outbreak of measles among Irish Travellers in England, March to May 2007. Euro Surveill. 2007;12(24). pii=3216. Available from: http://www.eurosurveillance.org/ViewArticle. aspx?Articleld $=3216$

17. Løvoll $\varnothing$, Vonen L, Nordbø SA, Vevatne T, Sagvik E, Vainio $\mathrm{K}$, et al. Outbreak of measles among Irish Travellers in Norway: an update. Euro Surveill. 2007;12(24). pii=3217. Available from: http://www.eurosurveillance.org/ViewArticle. aspx?Articleld $=3217$

18. Curtale F, Perrelli F, Mantovani J, Atti MC, Filia A, Nicoletti L, et al. Description of two measles outbreaks in the Lazio Region, Italy (2006-2007). Importance of pockets of low vaccine coverage in sustaining the infection. BMC Infect Dis. 2010;10:62. Available from: http://www.ncbi.nlm.nih.gov/ pubmed/20219143

19. World Health Organization, Regional Office for Europe. Surveillance guidelines for measles and congenital rubella infection in the WHO European region. 2003. Page 1-72. Available from: http://www.euro.who.int/document/E82183. pdf

20. Rechel B, Blackburn CM, Spencer NJ, Rechel B. Access to health care for Roma children in Central and Eastern Europe: findings from a qualitative study in Bulgaria. Int J Equity Health. 2009;8:24. Available from: http://www.ncbi.nlm.nih. gov/pubmed/19566936

21. Centers for Disease Control and Prevention (CDC). Progress toward measles elimination--European Region, 2005--2008. MMWR Morb Mortal Wkly Rep. 2009;58(6):142-5. Available from: http://www.ncbi.nlm.nih.gov/pubmed/19229166 